\title{
Quality of life and its association with insomnia and clinical variables in type 2 diabetes
}

\author{
Original Akhilesh Jain Anekha Sharmab $^{2}$, Neelam Yadavc ${ }^{3}$, Pavan K. Chaudhary', Garima \\ Article \\ Jainc $^{3}$, Mukesh Maanju ${ }^{1}$
}

${ }^{1}$ Departments of Psychiatry, ${ }^{2}$ Ophthalmology, ${ }^{3}$ Medicine, ESIC Model Hospital, Jaipur, India

\begin{abstract}
Background: There is a significant increase in number of patients with type II diabetes, Quality of Life (QOL) has become a major concern. Insomnia associated with diabetes may also influence QOL in these patients.

Aim: This cross sectional comparative study aims to assess QOL and its determinants inpatients with type 2 diabetes (T2DM). It also explored the prevalence and association of insomnia with QOL in T2DM patients.

Materials and Methods: The sample size comprised of 50 patients with T2DM and equal number of healthy control. Socio demographic and disease characteristics were recorded on a specially designed Performa. QOL and insomnia were assessed on WHOQOL-BREEF and ISI, respectively.

Results: The mean age of participants was $48.25 \pm 19.05$ years and the mean duration of illness was $5.64 \pm 2.35$ years. QOL was significantly impaired in all the four domains of WHOQOLBREF $(p<0.05)$. Female genders, poor glycemic control, longer duration of disease, increased BMI were associated with poor QOL. Insomnia was more common in diabetics [Odds Ratio (95\% C. I.=8.566 (3.321 to 22.094)] and had significant association with poor QOL.

Conclusions: QOL in patients with T2DM is impaired. Several disease characteristics have negative influence on QOL in these patients. Frequent occurrence of insomnia may further deteriorate the QOL.It is important to understand risk factors associated with poor QOL to formulate appropriate treatment strategy.
\end{abstract}

Received: 14 March 2017, Accepted: 07 October 2017

Key Words: Diabetes, insomnia, QOL.

Corresponding Author: Akhilesh Jain, MD, Department of Psychiatry, ESIC Model Hospital, Jaipur, India, Tel.: 919929241759, E-mail: brainwss@gmail.com

ISSN: 0013-2446, Vol. 92, No.1

\section{INTRODUCTION}

Diabetes is considered to have gained the status of a potential epidemic in India with more than 62 million individuals currently diagnosed with the disease ${ }^{[1,2]}$. Wild et $a l^{[3]}$ have predicted the prevalence of diabetes to get doubled globally from 171 million to 366 million in 2030 with maximum increase in India.

Type 2 diabetes mellitus (T2DM) imposes significant burden and impairs the quality of life (QOL) ${ }^{[4]}$. Persons with T2DM report lower health-related quality of life (HRQL) than the general population ${ }^{[5]}$. HRQL is regarded as an important measure of outcome in patients with T2DM as it has been used to evaluate the impact of the disease and its treatment on individuals. Worse HRQL is associated with higher mortality in persons with $\mathrm{T} 2 \mathrm{DM}^{[6]}$.

Poor sleep is a common feature of T2DM. Almost $25 \%$ of patients with sleep disorders and more than $75 \%$ patients experiencing at least one sleep symptom regularly have been reported in T2DM by Gupta and Wang ${ }^{[7]}$.
Difficulty initiating and maintaining sleep, daytime sleepiness, and poor sleep quality are some common sleep complaints encountered in patients with $\mathrm{T}_{2} \mathrm{DM}^{[8,9]}$. In a recent clinical trial, sleep quality was well correlated with other diabetes QOL score ${ }^{[10]}$. Sleep disorders have been reported to influence QOL adversely in T2DM as reported by Lou et al. ${ }^{[11]}$, who have found a positive association between poor sleep quality and HRQL.

Though there is enough evidence to suggest the overall low QOL in patients with T2DM, in India, the literature on the determinants of QOL and its correlation with insomnia is not largely available. The present study was designed to assess QOL and their determinants in T2DM. It has also explored the prevalence and association of insomnia with QOL.

\section{MATERIALS AND METHODS}

This study was conducted by the Department of Psychiatry in collaboration with the Diabetes Clinic of Medicine in a secondary care referral hospital in Jaipur, 
India. The hospital is a multispecialty treatment facility center catering to the health needs of a defined group of the population from the entire province. Diabetes patients are evaluated in detail in routine clinical practice, and all relevant biochemical tests are performed. The nature and purpose of the study were explained to all the participants, and informed consent was obtained before their inclusion in the study sample.

The study sample comprised 50 patients of diabetes from both sexes, between the ages of 18-70 years attending the outpatient clinic of diabetes department. Equal numbers of healthy controls were also enrolled to make a comparison group. Utmost care was taken to ensure the homogeneity of the sample population by recruiting close relatives or friends of the patients as a control group. Diabetes was defined as either requiring oral or injectable antidiabetic medication or having a random blood glucose level of above $200 \mathrm{mg} / \mathrm{dl}$.

The participants were excluded from the study if they were known: (i) to have current substance use disorder using the Diagnostic and Statistical Manual of Mental Disorders, 4th ed. (DSM-IV) criteria, (ii) to have current or past psychosis or mania, major depression, or any other mental disorder using the DSM-IV criteria, and (iii) to have any major medical or surgical problems before the diagnosis of diabetes.

\section{Measures}

A detailed evaluation of the sociodemographic and clinical profile was made on specially designed semistructured questionnaire by interviewing the participants for personal and sociodemographic details and obtaining information from the medical records for disease characteristics. This included the duration of illness, duration of treatment, the type of treatment, BMI, complications due to diabetes, fasting, and postprandial blood glucose levels. The participants were also assessed on Insomnia Severity Index (ISI) and WHOQOL-BREF to measure the presence of insomnia and QOL, respectively.

ISI $^{[12]}$ is one of the most commonly used diseasespecific measures for self-perceived insomnia severity. The ISI has seven items describing insomnia-related health impairments. Each item is rated on a five-point Likert scale with scores ranging from 0 to 4 , indicting 'none', 'mild', 'moderate', 'severe', and 'very severe' sleep problems, respectively. The total ISI score is calculated by summing the scores from the seven items, and range from a minimum of 0 to a maximum of 28 , with higher scores reflecting more severe sleep problems. In clinical assessments, the ISI total summary score falls into one of the four ISI categories, with scores $0-7,8-14,15-21$, and 22-28 indicating no clinically significant insomnia, subthreshold insomnia, moderate insomnia, and clinically severe insomnia, respectively. The psychometric properties of the ISI have been evaluated in earlier studies and have been reported to have sound measurement quality for measuring perceived insomnia severity and the impact of insomnia indifferent populations $^{[13,14]}$.

In our study, we used the Hindi version of the ISI $^{[15]}$, which has a reliability of 0.91 and a corrected item correlation range of $0.56-0.87$. The Hindi version of the SI is a self-reported, valid, and reliable tool for the measurement of severity of insomnia. A clinical cutoff score of 8 on the ISI is associated with optimal sensitivity and specificity for the detection of sleep difficulties ${ }^{[16]}$.

The WHOQOL-BREF ${ }^{[17]}$ was developed by the WHOQOL Group, in 15 international field centers ${ }^{[17]}$. It is a self-report questionnaire that contains 26 items, and each item represents one facet. Among the 26 items, 24 make up the four domains of physical health (seven items), psychological health (six items), social relationships (three items), and environment (eight items). The other two items measure the overall QOL and general health. In this study, the Hindi version ${ }^{[18]}$ was used. The scale has been shown to have good discriminate validity, sound content validity, and good test-retest reliability at several international WHOQOL centers. Despite the heterogeneity of facets included within domains, all domains display excellent internal consistency. Domain scores were calculated by multiplying the mean of all facet scores included in each domain by a factor of 4 , with a possible range of each raw domain score of 4 to 20. Each raw domain score was then transformed to a scale ranging from 0 to 100 , with a higher score indicating a higher QOL. The psychometric properties of the generic 236-item questionnaire was tested in several countries and the WHOQOL-100, Hindi tool was found to be a suitable instrument for comprehensively assessing the quality of life in health-care settings. The BREF version is shorter, simpler, and more convenient to be used in community survey and has better comprehensibility ${ }^{[18]}$.

Therefore, using the WHOQOL-BREF Hindi questionnaire in this study was suitable due to limited patient's time and busy clinical environments.

\section{Statistical analysis}

Data summarized and analyzed in MS Excel 2007 Medcalc version, 12.2.1.0 (Medcalc Software Mariakerke, Belgium) was used for the analysis of the data. univariate analysis for outcome variables of QOL, demographic profile, and insomnia. Independent unpaired t-test and analyses of variance were performed to find the association between QOL scores and various sociodemographic and clinical variables among the diabetic cases. Odds ratio was calculated to assess the degree of association of insomnia among diabetes cases and controls. The criterion for statistical significance was set at P less than 0.05 and for statistical trend at $\mathrm{P}$ less than 0.10 . 


\section{RESULTS}

\section{Sociodemographicprofileanddiseasecharacteristics of the participants}

A total of 50 patients and an equal number of agematched and sex-matched controls were included in the study. The mean age of the participants was $48.25 \pm 19.05$ and the mean duration of illness was $5.64 \pm 2.35$ years. Among the patients, 27 (54\%) were men and 27 (46\%) were women. Most of the patients $(80 \%)$ had been receiving treatment for more than 12 months. Thirty-three $(66 \%)$ had been taking oral medication as compared with six $(12 \%)$ of those receiving injections. Eleven $(22 \%)$ had been receiving both oral and injectable medications. Random blood sugar levels were above normal in 38
(76\%) of the study patients with the average blood glucose level measured as $153.06 \mathrm{mg} \%(\mathrm{SD}= \pm 59.25)$. Twenty-one $(42 \%)$ of the patients had optimal BMI, followed by 30 and $28 \%$ being overweight and obese, respectively. Current smoking was reported in $16(32 \%)$ of the diabetic patients.

\section{Mean QOL score in diabetes and control groups}

Table 1 shows the mean value of QOL related to all four domains in cases and controls as measured on WHOQOLBREF. On applying unpaired t-test, it was observed that the diabetic patient scores were significantly lower than the controls in all the four domains, including physical health (48.90 \pm 23.19 vs. $67.44 \pm 16.80)$, psychological health $(57.22 \pm 22.55$ vs. $69.52 \pm 17.74)$, social relationship $(53.88 \pm 23.96$ vs. $71.48 \pm 20.12)$ and environmental health $(55.60 \pm 22.25$ vs. $66.58 \pm 17.20)(P<0.05)$.

Table 1: Comparison of QOL scores in cases with Type 2 DM and controls at a diabetic clinic in secondary care hospital , 2016

\begin{tabular}{|c|c|c|c|}
\hline Domains & $\begin{array}{c}\text { Diabetes Group } \\
(\mathrm{N}=50) \text { Mean } \pm \mathrm{SD}\end{array}$ & $\begin{array}{c}\text { Control Group }(\mathrm{N}=50) \\
\text { Mean } \pm \mathrm{SD}\end{array}$ & Unpaired 't' test $P$ value LS \\
\hline Physical (D1) & $48.90 \pm 23.19$ & $67.44 \pm 16.80$ & $\begin{array}{c}4.578 \text { at } 98 \\
P<0.01^{*}\end{array}$ \\
\hline Psychological (D2) & $57.22 \pm 22.55$ & $69.52 \pm 17.74$ & $\begin{array}{c}3.031 \text { at } 98 \\
P<0.01^{*}\end{array}$ \\
\hline Social (D3) & $53.88 \pm 23.96$ & $71.48 \pm 20.12$ & $\begin{array}{c}3.978 \text { at } 98 \\
P<0.01^{*}\end{array}$ \\
\hline Environmental (D4) & $55.60 \pm 22.25$ & $66.58 \pm 17.20$ & $\begin{array}{c}2.761 \text { at } 98 \\
P<0.01^{*}\end{array}$ \\
\hline
\end{tabular}

* Significant, LS: Level of significance, D: Domain

\section{Relationship between sociodemographic profile and disease characteristics and $Q O L$ in diabetes}

The relationships of demographic variables and disease characteristics with QOL were examined (Table 2). The association of demographic variables with QOL score was statistically insignificant except that women had impaired QOL than men especially in the physical domain. Among the disease characteristics, QOL scores were significantly associated with $\mathrm{HbA} 1 \mathrm{C}$ level and patients with very good control (HbA1C level $\leq 6.5)$ had comparatively better QOL $(P<0.05)$ in all domains than those with poor control ( $\mathrm{HbA1C}$ level $\geq 8$ ). Similarly, the duration of illness had significant association with poor QOL $(P \leq 0.00)$. Patients who had diabetes for longer than 1 year scored significantly low than those patients with less than 1 year duration of illness in all four domains of QOL including physical health (39.39 vs. $73.36 \%$ ), psychological health (47.33 vs. $82.64 \%$ ), social health (43.47 vs. $80.64 \%$ ), and environmental health (46.22 vs. 79.71\%). Diabetic patients with BMI in overweight or obese range had poor QOL compared with their counterparts with low BMI $(P<0.001)$. Association of QOL scores with other disease factors such as the type of treatment, smoking, and random blood sugar level was found not significant in the present study. 
Table 2: Association of QOL scores with sociodemographic and clinical variables in cases with type 2 DM at a diabetic clinic in secondary care hospital , 2016

\begin{tabular}{|c|c|c|c|c|c|c|c|c|c|}
\hline \multirow[t]{2}{*}{ Variables } & \multirow[t]{2}{*}{$\mathrm{N}$} & \multicolumn{2}{|c|}{ Physical (D1) } & \multicolumn{2}{|c|}{ Psychological (D2) } & \multicolumn{2}{|c|}{ Social (D3) } & \multicolumn{2}{|c|}{ Environmental (D4) } \\
\hline & & Mean & $\mathrm{SD}$ & Mean & SD & Mean & $\mathrm{SD}$ & Mean & SD \\
\hline \multicolumn{10}{|l|}{ Age } \\
\hline$<50$ & 31 & 50.48 & 22.54 & 59.74 & 21.96 & 55.16 & 24.87 & 58.68 & 20.73 \\
\hline$\geq 50$ & 19 & 46.32 & 24.6 & 53.11 & 23.5 & 51.79 & 22.92 & 50.58 & 24.27 \\
\hline $\begin{array}{l}\text { Unpaired ' } t \text { ' } \\
\text { test P value } \\
\text { and LS }\end{array}$ & & \multicolumn{2}{|c|}{$P=0.612$ NS } & \multicolumn{2}{|c|}{$P=0.318 \mathrm{NS}$} & \multicolumn{2}{|c|}{$P=0.634 \mathrm{NS}$} & \multicolumn{2}{|c|}{$P=\begin{array}{l}1.257 \\
0.215 \mathrm{NS}\end{array}$} \\
\hline \multicolumn{10}{|l|}{ Sex } \\
\hline Male & 27 & 55.89 & 23.77 & 61.37 & 26.4 & 57.56 & 26.3 & 58.96 & 25.47 \\
\hline Female & 23 & 40.7 & 19.99 & 52.35 & 16.22 & 49.57 & 20.63 & 51.65 & 17.5 \\
\hline \multicolumn{2}{|l|}{$\begin{array}{l}\text { Unpaired 't' } \\
\text { test P value } \\
\text { and LS }\end{array}$} & \multicolumn{2}{|c|}{$P=0.019^{*}$} & \multicolumn{2}{|c|}{$P=0.161 \mathrm{NS}$} & \multicolumn{2}{|c|}{$P=0.244 \mathrm{NS}$} & \multicolumn{2}{|c|}{$P=0.251 \mathrm{NS}$} \\
\hline \multicolumn{10}{|l|}{$\begin{array}{l}\text { Duration } \\
\text { illness }\end{array}$} \\
\hline$\leq 1$ year & 14 & 73.36 & 22.8 & 82.64 & & 80.64 & 16.11 & 79.71 & 17.89 \\
\hline$>1$ year & 36 & 39.39 & 15.07 & 47.33 & & 43.47 & 17.6 & 46.22 & 15.82 \\
\hline $\begin{array}{l}\text { Unpaired ' } t \text { ' } \\
\text { test P value } \\
\text { and LS }\end{array}$ & & \multicolumn{2}{|c|}{$P=0.000 * *$} & $P=$ & $* *$ & $P=$ & & $P=$ & $* *$ \\
\hline BMI & & & & & & & & & \\
\hline$<24.99$ & 21 & 65.81 & 21 & 76.19 & 18.86 & 69.24 & 21.9 & 68.29 & 20.53 \\
\hline $25-25.99$ & 15 & 44.2 & 16.9 & 46.47 & 15.73 & 47.07 & 20.36 & 50.67 & 20.04 \\
\hline$\geq 30$ & 14 & 28.57 & 10.38 & 40.29 & 8.91 & 38.04 & 16.71 & 41.86 & 17.15 \\
\hline ANOVA & & & $0 * *$ & $P=$ & $0 * *$ & $P=$ & $0^{* *}$ & $P=$ & $0 * *$ \\
\hline $\begin{array}{l}\text { Type of } \\
\text { treatment }\end{array}$ & & & & & & & & & \\
\hline Oral & 33 & 50.12 & 24.88 & 58.79 & 24.13 & 56.03 & 27.16 & 55.52 & 23.68 \\
\hline Injectable & 6 & 57.67 & 24.61 & 59.83 & 28.71 & 57.67 & 21.58 & 61 & 28.75 \\
\hline Both & 1 & 40.45 & 14.89 & 51.09 & 12.78 & 45.36 & 10.78 & 52.91 & 13.92 \\
\hline ANOVA & & $P=$ & $\mathrm{NS}$ & $P=$ & NS & $P=$ & NS & $P=$ & NS \\
\hline $\begin{array}{l}\text { Blood sugar } \\
\text { (random) }\end{array}$ & & & & & & & & & \\
\hline$<140$ & 12 & 51.09 & 28.26 & 64.05 & 26.51 & 60.91 & 24.13 & 57.73 & 27.45 \\
\hline$>140$ & 38 & 48.28 & 21.94 & 52.51 & 21.38 & 51.9 & 23.85 & 55 & 32.26 \\
\hline $\begin{array}{l}\text { Unpaired ' } t \text { ' } \\
\text { test P value } \\
\text { and LS }\end{array}$ & & & NS & $P=$ & NS & $P=$ & NS & $P=$ & NS \\
\hline Smoking & & & & & & & & & \\
\hline Yes & 16 & 55.44 & 25.15 & 63 & 26.53 & 61.31 & 26.81 & 63.21 & 24.9 \\
\hline No & 34 & 45.82 & 21.91 & 54.5 & 20.28 & 50.38 & 22.06 & 52.24 & 20.13 \\
\hline $\begin{array}{l}\text { Unpaired 't' } \\
\text { test P value } \\
\text { and LS }\end{array}$ & & $P=$ & NS & $P=$ & NS & $P=$ & NS & $P=$ & NS \\
\hline
\end{tabular}




\begin{tabular}{|c|c|c|c|c|c|c|c|c|c|}
\hline \multicolumn{10}{|l|}{ HBalc } \\
\hline$<6.5$ & 7 & 74.17 & 6.77 & 83.67 & 10.46 & 72.33 & 18.98 & 80.67 & 14.68 \\
\hline$\leq 6.5-7.9$ & 11 & 62.27 & 28.53 & 70.9 & 22.26 & 68.45 & 29.33 & 69.73 & 21.49 \\
\hline$\geq 8$ & 32 & 39.85 & 17.2 & 47.45 & 17.36 & 45.67 & 18.65 & 46.33 & 17.47 \\
\hline ANOVA & & \multicolumn{2}{|c|}{$P=0.00^{* *}$} & \multicolumn{2}{|c|}{$P=0.000 * *$} & \multicolumn{2}{|c|}{$P=0.002 * *$} & \multicolumn{2}{|c|}{$P=0.002 * *$} \\
\hline \multicolumn{10}{|l|}{ Insomnia } \\
\hline Yes & 31 & 34.32 & 12.28 & \multicolumn{2}{|c|}{42.45} & \multicolumn{2}{|c|}{41.32} & 43.55 & 15.17 \\
\hline No & 19 & 72.68 & 15.78 & \multicolumn{2}{|c|}{81.32} & \multicolumn{2}{|c|}{74.37} & 75.26 & 17.5 \\
\hline \multicolumn{2}{|c|}{$\begin{array}{l}\text { Unpaired ' } \mathrm{t} \text { ' } \\
\text { test } \mathrm{P} \text { value } \\
\text { and LS }\end{array}$} & \multicolumn{2}{|c|}{$\begin{array}{c}9.612 \\
P=0.000 * *\end{array}$} & \multicolumn{2}{|c|}{$\begin{array}{c}10.946 \\
P=0.000 * *\end{array}$} & \multicolumn{2}{|c|}{$\begin{array}{c}6.358 \\
P=0.000^{* *}\end{array}$} & \multicolumn{2}{|c|}{$\begin{array}{c}6.767 \\
P=0.000 * *\end{array}$} \\
\hline
\end{tabular}

\section{Relationship between QOL and insomnia}

Table 3 explored the association between insomnia and diabetes. Insomnia was found in $31(62 \%)$ patients as measured on ISI. Diabetic cases had more than eight times chances of suffering from insomnia as compared with the control group [odds ratio $(95 \%$ confidence interval $=8.566$ (3.321-22.094)].
Patients with insomnia scored lower than those without insomnia in all four domains of QOL, including physical health (34.32 vs. 72.68), psychological health (42.45 vs. 81.32$)$, social relationship (41.32 vs. 74.37$)$, and environmental health (43.55 vs. 75.26). These findings were statistically significant for all domains $(P<0.01)$ (Table 2).

Table 3: Association of insomnia in cases with Type 2 DM andcontrols at a diabetic clinic in secondary care hospital, India, 2016

\begin{tabular}{lcccc}
\hline & Total & Insomina & \\
\hline & & Yes & No & $\begin{array}{c}\text { Odds Ratio } \\
(95 \% \text { C. I. })\end{array}$ \\
Cases & 50 & 31 & 19 & 8.566 \\
Controls & 50 & 8 & 42 & $(3.321$ to 22.094) \\
\hline
\end{tabular}

\section{DISCUSSION}

QOL in patients with diabetes was significantly impaired than in the healthy controls. Several studies have shown a strong negative influence of diabetes on $\mathrm{QOL}^{[19-21]}$. Furthermore, diabetic complications have been found to have an additional negative impact on QOL in such patients ${ }^{[22,23]}$.

QOL is an important aspect in patients with diabetes. Poor QOL may be associated with decreased self-care, poor compliance, and increased complications that may exacerbate the existing illness, thus further deteriorating QOL. It also provides an opportunity to understand perceived burden in the patients and quantify the effect of treatment ${ }^{[24]}$.

Presence of insomnia in patients with diabetes predisposes them to develop further complications and may cause exacerbation of symptoms of diabetes. It is important to assess sleep quality in patients with T2DM as many patients may become aware of their sleep problems $^{[25]}$.

In this study sample, more than half of the participants $(62 \%)$ with diabetes had insomnia. Similar results have been reported in earlier studies. Luyster and Dunbar$\mathrm{Jacob}^{[10]}$ reported poor sleep quality in $55 \%$ of his study population with T2DM. Some other studies have also identified poor sleep quality ranging from 33 to as high as $67 \%$ in patients with $\mathrm{T}_{2} \mathrm{DM}^{[8,11,26,27]}$.

The underlying association between diabetes and insomnia can be explained by various factors such as hyperglycemia ${ }^{[2]}$, activation of HPA axis ${ }^{[28]}$, and impaired glucose tolerance ${ }^{[29]}$. Sleep apnea, commonly reported in diabetes ${ }^{[30]}$, may also contribute to poor sleep quality. Insomnia itself predisposes an individual with T2DM to further complications. During sleep deprivation high levels 
of glucose have been reported due to the reduced glucose metabolism and high cortisol level which may further aggravate diabetes ${ }^{[31]}$.

Factors affecting QOL in T2DM were also studied. Poor QOL was associated with female sex, longer duration of disease, poor glycemic control, increased BMI, and insomnia. Association between poor QOL and being women has also been reported by Manjunath et al. ${ }^{[32]}$ who after deriving the mean score of QOL scale, divided the groups between good score and bad scores. The corresponding findings have also been observed by Wexler et al. ${ }^{[23]}$ who studied 904 primary care patients with T2DM.

The duration of the illness also had an adverse influence on QOL in T2DM. Longer duration was associated with poor QOL. Lou et al. ${ }^{[11]}$ who studied 944 patients with diabetes established a similar association. Brasil et al. ${ }^{[33]}$ in his study also reported direct correlation of Diabetes Quality of Life Measure with time since the diagnosis of the illness. Longer duration is likely to be associated with poor adherence to treatment, increased complications including macrovascular and microvascular, escalation of financial burden, poor social participation, contributing to poor quality of life.

Association of poor glycemic control with impaired QOL observed in this study has also been reported in earlier studies ${ }^{[1,33]}$. Poor glycemic control not only gives rise to several complications, but also decreases the mobility and increases the mortality influencing QOL adversely.

Decreased score of QOL scale in this study was linked with increased BMI. Several studies in the recent past have yielded similar results ${ }^{[34,35]}$. Although this association was statistically significant with all domains of QOL, physical domain was most adversely affected with higher BMI corresponding to a qualifying score of at least 30 for obesity. Slagter et al. ${ }^{[35]}$ who studied 13686 individuals with obesity also observed the strong association of obesity with physical health domain as compared with other domains. It is postulated that individuals with obesity tend to carry more weight and have to put in much effort to perform daily activities. Moreover, obesity also predisposes an individual for several metabolic syndromes, diabetes, and other complications, thus impairing the QOL in such patients. Some studies on the contrary did not find any such correlation between obesity and impaired QOL like Manjunath et al. ${ }^{[32]}$, who cited the reason for this disparity being the small number of patients with obesity $(\geq 30)$ in his study sample as most of the participants had a BMI of between 27 and 30, who may have had still a good QOL. Similarly, Wexler et al. ${ }^{[23]}$ also did not find such association in his study.

Impaired QOL in our study was associated with insomnia. Lou et al. ${ }^{[11]}$ has also made a similar observation in his cross-sectional study to examine sleep quality and QOL in T2DM in the Chinese population. Luyster and Dunbar-Jacob ${ }^{[10]}$ also found poor sleep quality as a significant predictor of lower HRQL as indicated by a lower score on both the physical and mental component scores of SF-36. Guereje et al. ${ }^{[36]}$, who studied 2152 elderly Nigerians observed that difficulty in initiation or maintaining sleep and early morning awakening were associated with all four domains of WHOQOL-BREF and overall QOL. Insomnia causes significant impairment in social and occupational functioning, reduced capacity to work, frequent absenteeism, cognitive decline, and increased psychological comorbidities. Insomnia also aggravates the existing illness and may give rise to secondary complications affecting QOL in these patients $^{[10]}$.

\section{LIMITATIONS OF STUDY}

There are some limitations to the present study. The small sample size and the cross-sectional nature of the study may limit the applicability of results in the general population. Self-reported questionnaire may have resulted in underreporting or overreporting of symptoms. Subjective sleep experience may not appropriately represent the objective sleep difficulties.

\section{CONCLUSION}

T2DM influenced QOL adversely. Insomnia tended to occur more frequently in such patients as compared with healthy population. Various disease characteristics have been associated with impaired quality of life in T2DM including the duration of disease, poor glycemic control, increased BMI, and presence of insomnia. Targeting these risk factors during the treatment of T2DM may improve the overall QOL in those patients.

\section{CONFLICT OF INTEREST}

There are no conflicts of interest

\section{REFERENCES}

1. Joshi SR, Parikh RM. India - diabetes capital of the world: now heading towards hypertension J Assoc Physicians India 2007; 55:323-324.

2. Kumar A, Goel MK, Jain RB, Khanna P, Chaudhary V. India towards diabetes control: key issues. Australas Med J 2013; 6:524-531.

3. Wild S, Roglic G, Green A, Sicree R, King H. Global prevalence of diabetes-estimates for the year 2000 and projections for 2030. Diabetes Care 2004; 27:1047-1053

4. Volpato S, Maraldi C, Fellin R. Type 2 diabetes and risk for functional decline and disability in older 
persons. Curr Diabetes Rev 2010; 6:134-143.

5. Ribu L, Hanestad BR, Moum T, Birkeland K, Rustoen T. A comparison of the health-related quality of life in patients with diabetic foot ulcers, with a diabetes group and a nondiabetes group from the general population. Qual Life Res 2007; 16:179-189.

6. Kleefstra N, Houweling ST, Ubink- Veltmaat LJ, Logtenberg SJ, M de Jong, B Coyne, et al. Prediction of mortality in type 2 diabetes from healthrelated quality of life (ZODIAC-4). Diabetes Care 2008; 31:932-933.

7. Gupta S, Wang Z. Predictors of sleepdisorders among patients with type 2 diabetes mellitus. DiabetesMetabSyndr 2016; 10:213-220

8. Knutson KL, Ryden AM, Mander BA, Van Cauter E. Role of sleep duration and quality in the risk and severity of type 2 diabetes mellitus. Arch Intern Med 2006; 166:1768-1774.

9. Lopes LA, LinsCde M, Adeodato VG, Quental DP, de bruin PF, Montengro RM, et al. Restless legs syndrome and quality of sleep in type 2 diabetes. Diabetes Care $2005 ; 28: 2633-2636$.

10. Luyster FS, Dunbar-Jacob J. Sleep quality and quality of life in adults with type 2 diabetes. Diabetes Educ 2011; 379:347-355.

11. Lou P, Qin Y, Zhang P, Chen P, Zhang L, Chang $\mathrm{G}$, et al. Association of sleep quality and quality of life in type 2 diabetes mellitus: a cross-sectional study in China. Diabetes Res ClinPract 2015; 107:69-76.

12. Bastien $\mathrm{CH}$, Vallières $\mathrm{A}$, Morin $\mathrm{CM}$. Validation of the Insomnia Severity Index as an outcome measure for insomnia research. Sleep Med 2001; 2:297-307.

13. Sierra JC, Guillen-Serrano V, Santos-Iglesias P. Insomnia Severity Index: some indicators about its reliability and validity on an older adults sample. Rev Neurol 2008; 47:566-570.

14. Yu DS. Insomnia Severity Index: psychometric properties with Chinese community-dwelling older people. J Adv Nurs 2010; 66:2350-2359.

15. Lahan V, Gupta R. Translation and validation of the insomnia severity index in Hindi language. Indian $\mathrm{J}$ Psychol Med 2011; 33:172-176.

16. Savard MH, Savard J, Simard S, Ivers H. Empirical validation of the Insomnia Severity Index in cancer patients. Psychooncology 2005; 14:429-441.
17. Skevington SM, Lotfy M, O'Connell KA; WHOQOL Group. The World Health Organization's WHOQOLBREF quality of life assessment: psychometric properties and results of the international field trial. A report from the WHOQOL group. Qual Life Res 2004; 13:299-310.

18. Saxena S, Chandiramani K, Bhargava R. World Health Organization Quality of Life. WHOQOLHindi: a questionnaire for assessing quality of life in health care settings in India. Natl Med J India 1998; 11:160-165.

19. Eljedi A, Mikolajczyk RT, Kraemer A, Laaser U. Health-related quality of life in diabetic patients and controls without diabetes in refugee camps in the Gaza strip: a cross-sectional study. BMC Public Health 2006; 6:268.

20. Speight J, Reaney MD, Barnard KD. Not all roads lead to Rome - a review of quality of life measurement in adults with diabetes. Diabet Med 2009; 26:315-327.

21. Lee WJ, Song KH, Noh JH, Choi YJ, Jo MW. Health-related quality of life using the EuroQol 5D questionnaire in Korean patients with type 2 diabetes. J Korean Med Sci 2012; 27:255-260.

22. Rubin RR, Peyrot M. Quality of life and diabetes. Diabetes Metab Res Rev 1999; 15:205-218.

23. Wexler DJ, Grant RW, Wittenberg E, Bosch JL, Cagliero E, Delahanty L, et al. Correlates of healthrelated quality of life in type 2 diabetes. Diabetologia 2006; 49:1489-1497.

24. Vigneshwaran E, Padmanabhareddy Y, Devanna N, Alvarez-Uria G. Gender differences in health related quality of life of people living with HIV/AIDS in the era of highly active antiretroviral therapy. $\mathrm{N} \mathrm{Am} \mathrm{J}$ Med Sci 2013; 5:102-107.

25. Cunha MCB, Zanetti ML, Hass VJ. Sleep quality in type 2 diabetics. Rev Latino-Am Enfermagem 2008; $16: 850-855$.

26. Skomro RP, Ludwig S, Salamon E, Kryger MH. Sleep complaints and restless legs syndrome in adult type 2 diabetics. Sleep Med 2001; 2:417-422.

27. Lamond N, Tiggemann M, Dawson D. Factors predicting sleep disruption in Type II diabetes. Sleep $2000 ; 23: 415-416$.

28. Vgontzas AN, Chrousos GP. Sleep, the hypothalamicpituitary-adrenal axis, and cytokines: multiple interactions and disturbances in sleep disorders. 
Endocrinol Metab Clin North Am 2002; 31:15-36.

29. Hung HC, Yang YC, Ou HY, Wu JS, Lu FH, Chang CJ. The relationship between impaired fasting glucose and self-reported sleep quality in a Chinese population. Clin Endocrinol (Oxf) 2013; 78:518-524.

30. Einhorn D, Stewart DA, Erman MK, Gordon N, Philis-Tsimikas A, Casal E. Prevalence of sleep apnea in a population of adults with type 2 diabetes mellitus. EndocrPract 2007; 13:355-362.

31. Berglund G, Nilsson PM, Roost M, Engstrom G, Hedblad B. Incidence of diabetes in middle-aged men is related to sleep disturbances. Diabetes Care 2004; 27:2464-2469.

32. Manjunath K, Christopher P, Gopichandran V, Rakesh PS, George K, Prasad JH. Quality of life of a patient with type 2 diabetes: across-sectional study in rural south India. J Fam Med Prim Care 2014; 3:396-399.
33. Brasil F, Souza RAP, Pontarolo R, Correr CJ. Evaluation of the quality of life in Brazilian diabetic patients: comparison between specific and generic free instruments. Int J Diabetes Developing Countries 2015; 35 (Suppl):201-204.

34. Hlatky MA, Chung SC, Escobedo J, Hillegass WB, Melsop K, Rogers W, Brooks MM. BARI 2D Study Group. The effect of obesity on quality of life in patients with diabetes and coronary artery disease. Am Heart J 2010; 159:292-300.

35. Slagter SN, van Vliet-Ostaptchouk JV, van Beek AP, Keers JC, Lutegers HL, van der Klauw MM, et al. Health-related quality of life in relation to obesity grade, type 2 diabetes, metabolic syndrome and inflammation. PLoS One 2015; 10:e0140599.

36. Guereje O, Kola L, Ademola A, Olley BO. Profile comorbidity and impact of insomnia in the Ibadan study of ageing. Int J Geriatr Psychiatry 2009; 24:686-693. 